\title{
Cerebral palsy in the surviving twin associated with infant death of the co-twin
}

\author{
P O D Pharoah
}

\begin{abstract}
Background-Monozygotic twins are at greater risk of dying and of serious morbidity than dizygotic twins, and both are at greater risk than singletons. This is only partly explained by the higher proportion of low birthweight infants among twins.

Aim-To compare, in same sex and different sex twins, birth weight specific neonatal death rates and cerebral palsy prevalence rates in the surviving twin when the co-twin has died in infancy.

Methods-Analysis of birth and death registration data for same sex and different sex twins for England and Wales 19931995 where both were live births. Death certificates of all liveborn twins who died were obtained from the Office for National Statistics. A questionnaire was sent to the general practitioners of all surviving cotwins to determine if the child had any disability.
\end{abstract}

Results-The neonatal death rate in same sex twins was 25.4 and in different sex twins 18.0 per 1000 live births (death rate difference $7.4 ; 95 \%$ confidence interval 4.7 to $10.1 ; p<0.001)$. The higher neonatal death rate in same sex compared with different sex twins is attributable to the higher proportion of same sex twins with low birth weight. Prevalence of cerebral palsy in the low birthweight group $(<1000$ g) was marginally higher in same sex (224 per 1000) than different sex (200 per 1000) twin survivors. In the birth weight group 1000-1999 g, same sex twin survivors were at a significantly higher risk of cerebral palsy than those of different sex: $167 v 21$ per 1000; difference 145 (95\% confidence interval 44 to 231 ; $p<0.01$ ) per 1000 infant survivors.

Conclusion-There are two components to the cause of cerebral palsy in twins. Immaturity per se predisposes to cerebral damage. Also, same sex twins may sustain cerebral damage that is in excess of that due to immaturity.

(Arch Dis Child Fetal Neonatal Ed 2001;84:F111-F116)

and Paediatric

Epidemiology,

Muspratt Building,

Department of Public

Health, University of

Liverpool, Liverpool

L69 3 GB, UK

P O D Pharoah

Correspondence to Professor Pharoah

p.o.d.pharoah@liv.ac.uk

Accepted 15 November 2000
Keywords: twins; monozygotic; dizygotic; death rate; cerebral palsy; birth weight

Although crude prevalence rates of cerebral palsy are higher in twins than singletons, birth weight specific rates show that significant differences between twins and singletons are confined to those of birth weight $\geqslant 2500 \mathrm{~g}^{1-3}$ In part, the higher crude prevalence rate of cerebral palsy is attributable to the higher proportion of twins of low birth weight than found for singletons. Also some of the increased risk of cerebral palsy in twins compared with singletons is associated with the fetal death of one twin and is probably specific to monochorionic twining. ${ }^{4-6}$ In such cases, it is likely that the cerebral palsy in the surviving twin is attributable to prenatal damage arising from problems associated with placental vascular anastomoses and haemodynamic changes from twin-twin transfusion.

Although national birth and death registration data do not allow differentiation of twin pairs according to chorionicity or zygosity, differentiation into same sex and different sex twins is available. Therefore, when both twins are live births, mortality and cerebral palsy in one twin after death of the co-twin can be compared for same and different sex twins.

The study reported here compares same sex and different sex twins with respect to mortality and cerebral palsy prevalence among the survivors when one of a twin pair has died.

\section{Methods}

The study was part of a larger one, the methods of which have been reported previously. ${ }^{6}$

All registered twin live births in England and Wales for 1993-1995 comprise the database. Routinely published data on live birth and death registrations of twins according to sex were used. Birth weight was grouped in $500 \mathrm{~g}$ class intervals.

Weinberg's rule was applied to the number of live births in each birth weight group in table 1. The rule assumes that all different sex twins must be dizygotic and that there are an equal number of dizygotic same sex twins. ${ }^{7}$ This allows the number of monozygotic and dizygotic twins in a population sample of twins to be estimated. This may be explained as follows: the total number of twin pairs $=\mathrm{N}$; the number of different sex twin pairs $=\mathrm{x}$, these must all be dizygotic; there are an equal number of same sex twin pairs that are dizygotic so that the total number of dizygotic twin pairs $=2 x$; therefore the estimated number of monozygotic twin pairs $=\mathrm{N}-2 \mathrm{x}$.

Where both twins were live births and either one or both twins died, the Office for National Statistics (ONS) provided copies of the nonconfidential part of the death certificate. This allowed the causes of death and the age at death to be analysed. The analyses were grouped according to whether the twins were of the same or different sex.

For all surviving twins whose co-twin had died, the ONS sent a questionnaire with a covering letter to the general practitioner of the 


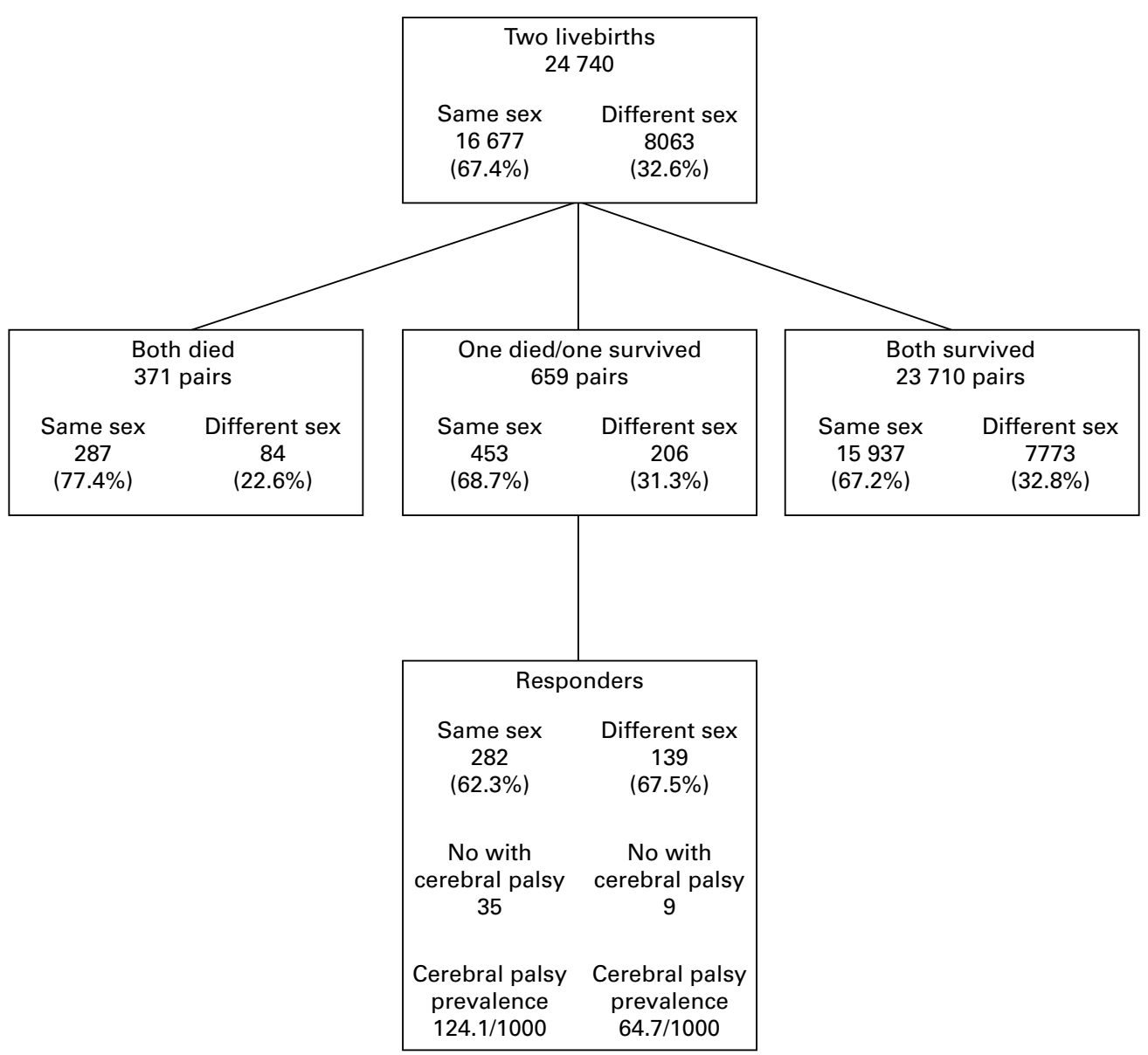

Figure 1 Distribution of same and different sex twin live births in England and Wales 1993-1995.

surviving child. Two questions comprised part of the questionnaire:

(1) Has this child got any disability? If Yes, please describe-for example, hearing, vision, physical disability.

(2) Is this child known to have cerebral palsy? If Yes, please specify the type-for example, diplegia, hemiplegia, quadriplegia, dyskinetic, mixed.

The covering letter to the general practitioner explained the objective of the research and made it discretionary whether or not the parents gave permission for the general practitioner to release the information. It was made discretionary on the advice of the two ethical committees that approved the research. The general practitioner was allowed discretion because the co-twin of the surviving child had died, and, as this was the reason for seeking information, the parents may have been unduly stressed by reviving the earlier experience of the child's death.

The returned questionnaires were analysed according to whether the liveborn twin was of the same or different sex as the co-twin who had died.

The immediate, underlying, and contributory causes of death on the death certificate were examined for mention of cerebral palsy, cerebral infarction, cerebral atrophy, or cerebral cystic lesions as indicators of cerebral ischaemic damage.
STATISTICAL METHODS

The difference between two independent proportions was examined using the $\chi^{2}$ test. Trend in proportions was examined by the $\chi^{2}$ test for linear trend. ${ }^{8}$

\section{Results}

In England and Wales in 1993-1995, there were 24740 twin pairs in which both were live births. Of these, $16677(67.4 \%)$ were of the same sex and 8063 (32.6\%) were of different sex (fig 1).

In 371 pairs, both twins died; these comprised 571 infant and three child deaths among same sex pairs and 167 infant and one child death among different sex pairs.

In 659 pairs, one twin died and the co-twin survived; the twins that died comprised 437 infant and 16 child deaths among same sex pairs and 197 infant and nine child deaths among different sex pairs.

A response from the general practitioner was received for 282 of the 453 twins from same sex pairs, a response rate of $62.3 \%$. Of 206 different sex co-twin survivors, a response was obtained for 139 , a response rate of $67.5 \%$ (fig 1). The difference in the response rate between same and different sex pairs (difference 5.2\%; $95 \%$ confidence interval (CI) $-2.7 \%$ to + $12.8 \% ; \mathrm{p}=0.2)$ is not significant. 
Table 1 Comparison of neonatal mortality in same sex and different sex twins: England $\mathcal{G}$ Wales 1993-1995

\begin{tabular}{|c|c|c|c|c|c|c|c|c|}
\hline \multirow[b]{2}{*}{ Birth weight } & \multicolumn{3}{|l|}{ Same sex } & \multicolumn{3}{|l|}{ Different sex } & \multirow[b]{2}{*}{$\begin{array}{l}\text { Same - different sex difference in } \\
\text { neonatal death rate }(95 \% \mathrm{CI}) ; p \\
\text { value }\end{array}$} & \multirow{2}{*}{$\begin{array}{l}\text { Estimated } \\
\text { proportion of } \\
\text { monozygotic } \\
\text { twins (\%) }\end{array}$} \\
\hline & $\begin{array}{l}\text { Number of } \\
\text { live births }\end{array}$ & $\begin{array}{l}\text { Number of } \\
\text { neonatal } \\
\text { deaths }\end{array}$ & $\begin{array}{l}\text { Neonatal } \\
\text { death } \\
\text { rate/1000 }\end{array}$ & $\begin{array}{l}\text { Number of } \\
\text { live births }\end{array}$ & $\begin{array}{l}\text { Number of } \\
\text { neonatal } \\
\text { deaths }\end{array}$ & $\begin{array}{l}\text { Neonatal } \\
\text { death } \\
\text { rate/1000 }\end{array}$ & & \\
\hline Not stated & 829 & 63 & 76.0 & 392 & 26 & 66.3 & $9.7(-23.5$ to +38.7$) ; 0.06$ & 35.8 \\
\hline$<500 \mathrm{~g}$ & 99 & 78 & 787.9 & 32 & 27 & 843.8 & $-55.9(-186.6$ to +120.7$) ; 0.5$ & 51.1 \\
\hline $500-999 \mathrm{~g}$ & 942 & 432 & 458.6 & 366 & 131 & 357.9 & $100.6(41.2$ to 158.1$) ;<0.001$ & 44.0 \\
\hline $1000-1499 \mathrm{~g}$ & 1902 & 129 & 67.8 & 721 & 56 & 77.7 & $-9.8(-34.0$ to +11.4$) ; 0.3$ & 45.0 \\
\hline $1500-1999 \mathrm{~g}$ & 4567 & 49 & 10.7 & 1929 & 17 & 8.8 & $1.9(-3.9$ to +6.7$) ; 0.5$ & 40.6 \\
\hline $2000-2499 \mathrm{~g}$ & 9707 & 36 & 3.7 & 4472 & 11 & 2.5 & $1.2(-0.9$ to +3.1$) ; 0.2$ & 36.9 \\
\hline $2500-2999 \mathrm{~g}$ & 10855 & 27 & 2.5 & 5601 & 10 & 1.8 & $0.7(-1.0$ to +2.1$) ; 0.4$ & 31.9 \\
\hline $3000-3499 \mathrm{~g}$ & 3912 & 12 & 3.1 & 2280 & 5 & 2.2 & $0.9(-2.3$ to +3.5$) ; 0.5$ & 26.4 \\
\hline$\geqslant 3500 \mathrm{~g}$ & 540 & 22 & 40.7 & 333 & 7 & 21.0 & $19.7(-5.5$ to +43.1$) ; 0.1$ & 23.7 \\
\hline Total & 33353 & 848 & 25.4 & 16126 & 290 & 18.0 & $7.4(4.7$ to 10.1$) ;<0.0001$ & 34.8 \\
\hline
\end{tabular}

BIRTH WEIGHT SPECIFIC NEONATAL DEATH RATES The crude neonatal death rate of 25.4 per 1000 same sex twins differed significantly from that of different sex twins at 18.0 per 1000 live births $(p<0.0001)$. However, in only one of the birth weight specific groups (500-999 g) was the neonatal death rate significantly different in same sex and different sex twins (table 1). The significant difference in same sex and different sex crude neonatal death rates therefore has two components. There is an increasing proportion of same sex compared with different sex twins with decreasing birth weight, and there is a higher neonatal death rate among same sex than different sex twins of birth weight 500-999 g. Excluding the birth weight "not stated" group, a $\chi^{2}$ for linear trend shows that the birth weight group distribution of same sex compared with different sex twins is highly significant $\left(\chi^{2}=152.2 ; 1 \mathrm{df} ; \mathrm{p}<0.0001\right)$.

After application of Weinberg's rule, in the lowest birthweight group $(<500 \mathrm{~g})$, the proportion of twins that are monozygotic is estimated to be $51.1 \%$. In the highest birthweight group ( $\geqslant 3500 \mathrm{~g}$ ), monozygotic twins comprise only $23.7 \%$. The trend in the relative proportion of monozygotic to dizygotic twins by birth weight group is highly significant $(\mathrm{p}<0.0001)$.

CEREBRAL PALSY IN TWIN SURVIVORS OF A CO-TWIN DEATH

The crude prevalence rate of cerebral palsy in the same sex survivor of a co-twin infant death (124 per 1000) is higher than that for a different sex twin survivor ( 65 per 1000), but the difference is not significant $(p=0.06)$. However, much of the difference in crude rate attributable to the difference in prevalence of cerebral palsy between same sex and different sex pairs is in the birth weight groups 1000-1499 g and 1500-1999 g. Combining the two groups, same sex twins are at significantly higher risk than different sex twins: 167 v 21 per 1000; difference 145 per 1000 (95\% CI 44 to 231 ; p < 0.01) (table 2).

Therefore, same sex compared with different sex twins are not only at increased risk of having a low birth weight with its attendant risk of cerebral impairment but, in addition, there is a higher prevalence of cerebral palsy in the lowest birthweight groups.

Table 3 shows clinical details of the surviving twin with cerebral palsy and the birth weight and age of death of the co-twin who died for same sex and different sex twins. There is no clear difference in the type of cerebral palsy found in the same sex and different sex twins.

CERTIFIED CAUSE OF DEATH IN SAME SEX AND DIFFERENT SEX TWINS

For twins who had died, among same sex twins there were six for whom cerebral palsy was the certified cause of death. Their ages at death ranged from 3 months to 19 months and their birth weights ranged from 1249 to $2580 \mathrm{~g}$. In one of these, twin to twin transfusion was also mentioned on the death certificate. In contrast, there were no cases of cerebral palsy in different sex twins who died.

In five same sex twins who died, cerebral infarction was the certified cause. Age at death ranged from 4 days to 4 months and their birth weights ranged from 1100 to $2700 \mathrm{~g}$. In one of these, twin to twin transfusion was also mentioned. There was also one case of severe ischaemic subcortical leucomalacia (age at death 13 days and birth weight $710 \mathrm{~g}$ ). There were no such cases among the different sex twins.

Cerebral atrophy was the certified cause of death in one same sex twin. The child died aged 21 months and weighed $2680 \mathrm{~g}$ at birth. One case of cerebral atrophy with subdural effusions following viral encephalitis was certified among the different sex twins. The child died age 13 months but no birth weight was registered.

Table 2 Comparison of cerebral palsy prevalence rates in same sex and different sex twins in survivors where the co-twin has died

\begin{tabular}{|c|c|c|c|c|c|}
\hline \multirow[b]{2}{*}{ Birth weight group } & \multicolumn{2}{|l|}{ Same sex } & \multicolumn{2}{|l|}{ Different sex } & \multirow[b]{2}{*}{$\begin{array}{l}\text { Same - different sex difference } \\
(95 \% \text { CI } ; p \text { value }\end{array}$} \\
\hline & $\begin{array}{l}\text { No of cerebral palsy/no of } \\
\text { responders }\end{array}$ & $\begin{array}{l}\text { Cerebral palsy prevalence } \\
\text { per } 1000 \text { infant survivors }\end{array}$ & $\begin{array}{l}\text { No of cerebral palsy/no of } \\
\text { responders }\end{array}$ & $\begin{array}{l}\text { Cerebral palsy prevalence } \\
\text { per } 1000 \text { infant survivors }\end{array}$ & \\
\hline$<1000 \mathrm{~g}$ & $17 / 76$ & 224 & $8 / 40$ & 200 & $24(-146$ to +170$) ; 0.7$ \\
\hline $1000-1499 \mathrm{~g}$ & $14 / 75$ & 187 & $1 / 32$ & 31 & 155 (15 to 266$) ; 0.02$ \\
\hline $1500-1999 \mathrm{~g}$ & $4 / 33$ & 121 & $0 / 15$ & 0 & $121(-94$ to +275$) ; 0.2$ \\
\hline$\geqslant 2000 \mathrm{~g}$ & $0 / 91$ & 0 & $0 / 48$ & 0 & - \\
\hline Not stated & $0 / 7$ & 0 & $0 / 4$ & 0 & - \\
\hline Total & $35 / 282$ & 124 & $9 / 139$ & 65 & 59 ( -3 to 114$) ; 0.06$ \\
\hline
\end{tabular}


Table 3 Cerebral palsy in surviving twins

\begin{tabular}{|c|c|c|c|c|c|}
\hline \multicolumn{3}{|l|}{ Twin who died } & \multicolumn{3}{|c|}{ Twin who survived with cerebral palsy } \\
\hline Birth weight (g) & Age at death & Cause of death & Birth weight (g) & Type of cerebral palsy & General practitioner comments \\
\hline \multicolumn{6}{|l|}{ Same sex pairs } \\
\hline 550 & 5 months & Congenital brain anomaly & 570 & Not specified & Speech delay \\
\hline 500 & 1 hour & Severe prematurity & 600 & Quadriplegia & $\begin{array}{l}\text { Poor vision, profound disabilities, IVH leading } \\
\text { to hydrocephalus }\end{array}$ \\
\hline 680 & 22 days & Chorioamnionitis, septicaemia & 650 & Diplegia & \\
\hline 840 & 2 days & IVH & 660 & Diplegia & $\begin{array}{l}\text { Functioning at } 12-18 \text { month level } \\
\text { (chronological age } 3 \text { years) }\end{array}$ \\
\hline 980 & $<1$ hour & Extreme prematurity & 750 & Mixed & $\begin{array}{l}\text { Global delay, vision and physical disability, } \\
\text { microcephaly }\end{array}$ \\
\hline 1820 & $<1$ hour & Hydrops fetalis & 800 & Hemiplegia & Mild developmental delay \\
\hline 860 & 14 days & IVH, hydrocephalus & 804 & Not specified & Developmental delay in all areas \\
\hline 660 & 5 months & Extreme prematurity & 815 & R Hemiplegia & Slow to speak, late walking and crawling \\
\hline 1105 & 3 days & RDS & 830 & Diplegia & $\begin{array}{l}\text { Motor development delayed, mental } \\
\text { development in line with chronological age }\end{array}$ \\
\hline 840 & 11 weeks & Cerebral ischaemia & 840 & Hemiplegia & Toe walking, poor fine motor movements \\
\hline 850 & 11 days & IVH & 850 & Not specified & Developmental milestones delayed \\
\hline 840 & 4 months & $\mathrm{BPD}$ & 860 & Mixed & Mobility problems, cannot walk unaided \\
\hline 600 & 4 days & IVH & 862 & Diplegia & $\begin{array}{l}\text { Cerebral haemorrhage } \rightarrow \text { hydrocephalus } \rightarrow \\
\text { shunt }\end{array}$ \\
\hline Not stated & 13 days & Extreme prematurity & 900 & Not specified & $\begin{array}{l}\text { Every milestone late, especially language. } \\
\text { Weakness and } \uparrow \text { tone L leg }\end{array}$ \\
\hline 750 & 7 days & PVH, TTT & 910 & R Hemiplegia & Speech delayed, L periventricular leucomalacia \\
\hline 2100 & 33 days & Extreme prematurity, PVL & 940 & Quadriplegia & Global delay, epilepsy \\
\hline 960 & 3 days & RDS & 970 & Diplegia & Normal speech and understanding \\
\hline 1030 & 27 days & $\mathrm{NE}$ & 1030 & Diplegia & Speech delay \\
\hline 1080 & 1 day & Cerebral dysgenesis, IVH & 1040 & Quadriplegia & $\begin{array}{l}\text { Has achieved half the } 0-4 \text { month level early } \\
\text { movement skills aged } 3 \text { years }\end{array}$ \\
\hline 1070 & 1 day & IVH & 1070 & R Hemiplegia & $\begin{array}{l}\text { Delayed motor development and speech at } 16 \\
\text { months, aged } 3 \text { years }\end{array}$ \\
\hline 1060 & 2 days & IVH & 1070 & Quadriplegia & Global developmental delay, PVL \\
\hline 1250 & 26 days & Extreme prematurity & 1080 & Diplegia & \\
\hline 1050 & 7 days & IVH, NE & 1095 & L Hemiplegia & $\begin{array}{l}\text { Hydrocephalus with shunt, visual impairment, } \\
\text { epilepsy }\end{array}$ \\
\hline 1230 & 7 days & NE & 1100 & L Hemiplegia & IVH, hydrocephalus and shunt \\
\hline 840 & 5 days & Severe anaemia, TTT & 1110 & Quadriplegia & $\begin{array}{l}\text { Severe PVL, locomotor, hearing/speech, } \\
\text { eye/hand, performance delay }\end{array}$ \\
\hline 820 & 1 day & Edward's syndrome & 1120 & R Hemiplegia & Doing well at present \\
\hline 1200 & 7 months & SIDS & 1120 & Diplegia & $\begin{array}{l}\text { Delay in social, hearing/speech and } \\
\text { performance }\end{array}$ \\
\hline 780 & $<1$ hour & Anaemia, TTT & 1150 & Diplegia & Locomotor and speech delay \\
\hline 1040 & 3 months & Bronchiolitis & 1170 & L Hemiplegia & Speech and walking delayed \\
\hline 1165 & 17 days & IVH & 1265 & Quadriplegia & $\begin{array}{l}\text { Hydrocephalus arrested, gross motor } \\
\text { developmental delay, speech reasonable }\end{array}$ \\
\hline 2120 & 22 hours & Cardiomyopathy & 1340 & L Hemiplegia & Psychomotor retardation \\
\hline 1516 & 6 hours & Massive pneumothorax & 1548 & Diplegia & Milestones delayed \\
\hline 1300 & 22 days & NE & 1570 & Quadriplegia & Poor vision, milestones 1 year delayed \\
\hline 694 & 5 months & NE & 1610 & Diplegia & VP shunt, hydrocephalus \\
\hline 1700 & 1 day & Congenital abnormality of the lung & 1980 & Hemiplegia & Great speech difficulties, L hydronephrosis \\
\hline \multicolumn{6}{|l|}{ Different sex pairs } \\
\hline 655 & 6 days & Bilateral IVH & 622 & Diplegia & Developmental delay \\
\hline 658 & 15 days & IVH & 755 & Not specified & \\
\hline 720 & 2 hours & IVH & 880 & Not specified & $\begin{array}{l}\text { Hydrocephalus, mental age } 1 \text { year, } \\
\text { chronological age } 5 \text { years }\end{array}$ \\
\hline 1220 & 6 days & IVH & 900 & Quadriplegia & Brain cysts, microcephaly \\
\hline 920 & 4 days & IVH & 930 & L Hemiplegia & Gross motor development delayed by 6 months \\
\hline 915 & 4 days & IVH, pneumothorax & 940 & R Hemiplegia & $\begin{array}{l}\text { Hydrocephalus with VP shunt, speech and } \\
\text { language delay }\end{array}$ \\
\hline 980 & 4 days & IVH, pneumothorax & 940 & Diplegia & \\
\hline 1230 & 9 days & Pulmonary haemorrhage & 980 & Not specified & Congenital hypothyroidism \\
\hline 980 & 27 days & Coarctation of the aorta & 1361 & Tetraplegia & Bilateral cystic PVL \\
\hline
\end{tabular}

IVH, Intraventricular haemorrhage; PVL, periventricular leucomalacia; TTT, twin to twin transfusion; SIDS, sudden infant death syndrome; RDS, respiratory distress syndrome; BPD, bronchopulmonary dysplasia; NE, necrotising enterocolitis.

Cerebral cystic abnormalities were recorded as the cause of death in three same sex and one different sex twin. In the same sex twins these were: bilateral porencephalic cystic leucomalacia (congenital), age at death 6 days, birth weight $1700 \mathrm{~g}$; multicystic leucoencephalopathy, age at death 2 days, birth weight 983 g; porencephaly, age at death 4 months, birth weight $1190 \mathrm{~g}$. As cystic cerebral abnormalities take 10-14 days to become clinically recognisable by imaging, ${ }^{9-12}$ the cerebral impairment in the two twins who died within a few days of birth must have occurred prepartum.

One different sex twin died from bilateral cystic leucomalacia aged 29 days and weighing $822 \mathrm{~g}$ at birth.

\section{Discussion}

Significant differences in neonatal mortality and cerebral palsy prevalence were observed in same sex compared with different sex twins. Unfortunately, national data do not allow a more precise separation of same sex into monozygotic and dizygotic twins, although the application of Weinberg's rule may allow an estimate to be made of their relative proportions. Probably of greater clinical relevance was whether the monozygotic twins were monochorionic, with the associated problems attributable to twin to twin transfusion. Access to obstetric case notes would have allowed a better assessment of whether the chorionicity of the placenta was a specific risk. Also neonatal 
imaging records may have allowed assessment of the timing of the cerebral impairment in those that presented with a clinical disability.

The response rate for same sex twins was $62.3 \%$, and for different sex twins it was $67.5 \%$. This raises a concern over the possibility of non-response bias. Of crucial importance is whether a response was more or less likely depending on whether a disability was present. Unfortunately the data do not allow assessment of such a bias. However, even on the assumption that all the non-responders were free of disability, the cerebral palsy prevalence rates would be very significantly higher than the rates in all twins observed in cerebral palsy registers.

An important observation from this study was the strong trend in the relative proportions of monozygotic and dizygotic twins with decreasing birth weight. Presumably a similar trend would be observed with decreasing gestational age but, because gestational age is not recorded at the registration of a live birth, this must remain an assumption. This trend in the relative proportion of monozygotic and dizygotic twins is probably the consequence of twin to twin transfusion among monochorionic twins with its predisposition to premature labour.

Undoubtedly, severe immaturity of an infant predisposes to cerebral impairment as a result of periventricular leucomalacia or haemorrhage and the attendant risk of cerebral palsy. The birth weight specific cerebral palsy prevalence rates for the different sex twins shown in table 2 cannot be circulatory consequences of twin to twin transfusion and are likely to be attributable to cerebral impairment as a direct consequence of the immaturity of the infant. As a corollary to the data presented in table 2, it is proposed that cerebral palsy in apparently singleton infants has predominantly two components. One component is immaturity with its attendant risk of hypoxic ischaemic cerebral impairment occurring post partum. This component would have birth weight specific prevalence rates of cerebral palsy similar to that in different sex twins. Because for a given birth weight, twins tend to be gestationally more mature than singletons, such an assumption is not strictly valid; nevertheless, an estimate should not be grossly inaccurate. The second component is the cerebral impairment associated with monochorionic twinning where one twin has succumbed in utero, either as a "vanishing" twin or as a fetus papyraceous which has not been registered.

Same sex twins had higher birth weight specific cerebral palsy prevalence rates than different sex twins. It must be assumed that, in addition to the immaturity, some other factor is contributing to the cerebral impairment in these infants. One possibility is that same sex twins are genetically more vulnerable to neonatal complications. However, even within monozygous and therefore genetically identical twins, the increased risk of death and cerebral impairment is predominantly limited to monochorionic twins. ${ }^{13}{ }^{14}$ Therefore a genetic predisposition is an unlikely explanation, and a more probable one is cerebral ischaemia as a consequence of haemodynamic disturbance from twin to twin transfusion. Such cerebral impairment cannot occur postnatally because placental circulatory communication between the twins has by then been severed. Cerebral palsy and other cerebral impairments have also been observed in same sex twin pregnancies in which one twin died in utero. ${ }^{6}$ An anomaly in these data is the lack of a significant difference in cerebral palsy prevalence between same sex and different sex twins for the lowest birthweight $(<1000 \mathrm{~g})$ group. This may be explained as being an artefact of differential survival. The same sex twins would have higher rates of prenatally determined cerebral palsy, but such cerebral damage in addition to their severe immaturity leads to early death so that it is not clinically recognised. This explanation is supported by the very significantly higher neonatal mortality in same sex twins of the birth weight group 500-999 g (table 2).

Not only do same sex compared with different sex twins have higher birth weight specific cerebral palsy prevalence rates, but they are disproportionately highly represented among the lowest birthweight groups. Thus same sex twins make a dual contribution to the high cerebral palsy rates found in twins. One possible explanation is that twin to twin transfusion in monochorionic twins, as a subset of same sex twins, predisposes to both early labour and cerebral impairment. Alternatively, prenatal cerebral ischaemia as a consequence of haemodynamic changes from twin to twin transfusion may be a mechanism that precipitates early labour.

The data reported here complement previously reported data on cerebral palsy and cerebral impairment in surviving twins when the co-twin has died in utero. ${ }^{6}$ As the study reported here investigated only twins in which both were live births but one subsequently died, it has a disproportionately high number of infants of very low birth weight. Further epidemiological investigation is needed to determine the prevalence of cerebral palsy in twins where both survived. Such a study would include all twins in the higher birthweight groups. If twin to twin transfusion is the mechanism for the excess of cerebral palsy among low birthweight twins reported in this study, the prediction is that, in the higher birthweight groups, twins with cerebral palsy will predominate among same sex pairs.

I am grateful to The Foundation for the Study of Infant Death (FSID) which funded the study, to the general practitioners who cooperated in the study, and to the many parents who gave permission for details on the children to be released. I would also like to thank Beverley Botting, Lyn Aindow, and Sharon Rimmer of ONS for providing birth and death registration data and for organising the distribution of the survey letters and questionnaires.

1 Grether JK, Nelson KB, Cummins SK. Twinning and cerebral palsy in four northern Californian counties: births 1983 through 1985. Pediatrics 1993;92:854-8.

2 Petterson B, Nelson KB, Watson L, et al. Twins, triplets and cerebral palsy births in Western Australia in the $1980 \mathrm{~s}$. BMF 1993;307:1239-43.

3 Pharoah POD, Cooke T. Cerebral palsy and multiple births. Arch Dis Child 1996;75:F174-7. 
4 Rydhström $\mathrm{H}$, Ingemarsson I. Prognosis and long-term follow-up of a twin after antenatal death of a co-twin. $\mathcal{F}$ follow-up of a twin after ante
Reprod Med 1993;38:142-6.

5 Ishimatsu J, Hori D, Miyajima T, et al. Twin pregnancies complicated by the death of one fetus in the second or third trimester. Fournal of Maternal and Fetal Investigation $1994 ; 4: 141-5$

6 Pharoah POD, Adi Y. The consequences of fetal death in a twin pregnancy. Lancet 2000;355;1597-602.

7 Weinberg W. Beiträge zur physiologie und pathologie der mehrlingsgeburten beim menshem. Archiv für die gesamt Physiologie des Menschen und der Tiere 1902;88:346-430.

8 Armitage P. Tests for linear trends in proportions and frequencies. Biometrics 1955;11:375-86.

9 Weindling AM, Rochefort MJ, Calvert SA, et al. Development of cerebral palsy after ultrasonographic detection of periventricular cysts in the newborn. Dev Med Child Neuperiventricular cysts
10 Dubowitz LMS, Bydder GM, Mushin J. Developmental sequence of periventricular leucomalacia: correlation of ultrasound, clinical and nuclear magnetic resonance functions. Arch Dis Child 1985;60:349-55.

11 Tamisari L, Vigi V, Fortini C, et al. Neonatal periventricular leukomalacia: diagnosis and evolution evaluated by real-time ultrasound. Helvetica Paedriatrica Acta real-time ultraso

12 Levene MI. Cerebral ultrasound and neurological impairment: telling the future. Arch Dis Child 1990;65:469-71.

13 Sebire NJ, Snijders JM, Hughes K, et al. The hidden mortality of monochorionic twin pregnancies. $\mathrm{Br} F$ Obstet Gynecol 1997;104:1203-7.

14 Brodtkorb E, Myhr G, Gimse R. Is monochorionic twinning a risk factor for focal cortical dysgenesis? Acta Neurol Scand 2000;102:53-9. 